\title{
Pupil abnormality in amyloidosis with autonomic neuropathy
}

\author{
D R Davies, S E Smith
}

\begin{abstract}
Darkness pupil diameters, light reflexes, and redilatation times have been recorded with infrared TV pupillometry in 12 consecutive patients with systemic amyloidosis associated with sensory motor and autonomic neuropathy. Nine of the patients had AL amyloidosis, two had familial amyloidosis associated with a transthyretin abnormality, and one was untyped. The pupils were abnormal in all 12 patients. On the basis of redilatation lag without pupillotonia, six patients had bilateral Horner's syndrome and in one of them amyloid deposits were found in a sympathetic ganglion and in the attached sympathetic chain obtained at necropsy. Four patients had bilateral tonic pupils with light-near dissociation and two had abnormally small pupils with reduced light reactions which could not be characterised. It seems that in patients with systemic amyloidosis generalised autonomic neuropathy is strongly associated with pupil abnormality as shown by tonic reactions with light-near dissociation, by redilatation lag, or by reduced size in darkness.

(F Neurol Neurosurg Psychiatry 1999;67:819-822)
\end{abstract}

Department of Cellular Pathology, The John Radcliffe Hospital, Oxford, UK D R Davies

Department of

Neuro-Ophthalmology, National Hospital for

Neurology and

Neurosurgery, London, UK

S E Smith

Correspondence to: Professor SE Smith, Department of

Neuroophthalmology,

National Hospital for

Neurology and

Neurosurgery, Queen

Square, London WC1N

3BG, UK.

Received 14 December 1998 and in final form

27 May 1999

Accepted 9 June 1999
Keywords: amyloidosis; autonomic neuropathy; tonic pupil; Horner's syndrome

Clinical involvement of the autonomic nervous system is well recognised, although uncommon, in so called primary amyloidosis. Among patients who develop polyneuropathy, however, autonomic dysfunction seems to be common. Thus Trotter et $a l^{1}$ found orthostatic hypotension, bowel upset, and impotence in most such patients. Associated histopathological evidence exists in several case reports of amyloid deposition in sympathetic ganglia and chain. ${ }^{2-4}$

Ocular involvement is prominent in familial amyloidosis, ${ }^{5}$ although rare in primary amyloidosis. Pupillary abnormality has been reported, usually in association with other evidence of dysautonomia. We have found 12 such cases in the literature, the abnormality variously reported as hyporeactive,${ }^{6}$ unreactive $^{1}$ or showing light-near dissociation..$^{7-9}$ One report describes bilateral Holmes-Adie pupils showing denervation supersensitivity to methacholine. ${ }^{2}$ These abnormalities are consistent with a defect in the ocular parasympathetic nerves, for which amyloid deposition in the ciliary ganglion may be responsible. ${ }^{10}{ }^{11}$

It is surprising that no report exists of Horner's syndrome, particularly in that the abnormalities associated with autonomic neuropathy in amyloidosis usually include orthostatic hypotension, which may be caused by a sympathetic deficit. In this paper we report findings on 12 patients all having amyloidosis with orthostatic hypotension and pupil abnormality.

\section{Patients and methods}

PATIENTS

Twelve consecutive patients (five men, seven women) aged 32 to 70 years with biopsy or amyloidosis established by scan and autonomic failure were studied. In two patients the amyloidosis was familial (transthyretin proline 12 in one, proline 52 in the other), in nine the amyloidosis was biopsy typed as AL and one was untyped. Nine of the patients had peripheral sensorimotor neuropathy. All had orthostatic hypotension with reduced sinus arrhythmia (10 cases), reduced Valsalva response (10), dysphagia (five), diarrhoea (eight), constipation (two), impotence (four) and hypohidrosis (four). Slit lamp examination showed no ocular amyloid deposition except in the two patients with familial amyloidosis who had vitreous amyloid deposits but none in the irides or conjunctivae.

\section{PUPILLOGRAPHY}

Pupil diameters and their responses to light and accommodation were recorded without previous dark adaptation by infrared television pupillometry as previously described. ${ }^{12}$ Sympathetic function of the iris was assessed from measurement of dilator function, which is impaired in Horner's syndrome causing redilatation lag at the end of the light reflex. ${ }^{13}$ The index of redilatation time-the $t_{3 / 4}$ time-is defined as the time taken for the pupil to recover from its peak constriction during a light reflex three quarters of its way towards the initial darkness diameter. ${ }^{14}$ The results were compared with normal ranges previously established. ${ }^{14}$ Drug tests for detection of receptor supersensitivity were not performed because many of the patients had dry eyes. 
Pupil function

\begin{tabular}{|c|c|c|c|c|c|c|c|}
\hline \multirow[b]{2}{*}{$\begin{array}{l}\text { Patient Sex, } \\
\text { age }(y)\end{array}$} & \multirow[b]{2}{*}{ Amyloid type } & \multicolumn{2}{|c|}{ Darkness diameter ( $\mathrm{mm}$ ) } & \multirow{2}{*}{$\begin{array}{l}\text { Light reflex } \\
\text { amplitude } \\
(\mathrm{mm})\end{array}$} & \multicolumn{2}{|c|}{$t_{3 / 4}$ redilatation time $(s)$} & \multirow[b]{2}{*}{$\begin{array}{l}\text { Prevalent } \\
\text { abnormality }\end{array}$} \\
\hline & & Observed & $\begin{array}{l}\text { (Expected } \\
\text { range) }\end{array}$ & & Observed & $\begin{array}{l}\text { (Expected } \\
\text { range) }\end{array}$ & \\
\hline $1(\mathrm{~F}, 57)$ & AL & 3.69 & $4.3-7.1$ & 1.20 & 5.4 & $0.3-3.2$ & Redilatation lag \\
\hline $2(M, 57)$ & - & 4.05 & $4.3-7.1$ & 0.30 & - & - & Tonic \\
\hline $3(\mathrm{~F}, 58)$ & AL & 5.51 & $4.2-7.0$ & 2.08 & 4.1 & $1.0-3.9$ & Redilatation lag \\
\hline $4(M, 64)$ & AL & 6.60 & $3.9-6.7$ & 2.00 & 4.2 & $0.9-3.8$ & Redilatation lag \\
\hline $5(\mathrm{~F}, 61)$ & AL & 6.25 & $4.1-6.8$ & 1.32 & - & - & Tonic \\
\hline $6(\mathrm{~F}, 52)$ & $\mathrm{Fam}^{\star}$ & 4.45 & $4.5-7.3$ & 0.30 & - & - & Tonic \\
\hline $7(\mathrm{~F}, 52)$ & $\mathrm{AL}$ & 6.60 & $4.5-7.3$ & 1.68 & 6.1 & $0.7-3.6$ & Redilatation lag \\
\hline $8(M, 70)$ & AL & 5.71 & $3.6-6.3$ & 1.82 & 3.9 & $0.8-3.7$ & Redilatation lag \\
\hline $9(\mathrm{~F}, 32)$ & Fam $\dagger$ & 3.00 & $5.5-8.2$ & 0 & - & - & Tonic \\
\hline $10(M, 64)$ & AL & 3.10 & $3.9-6.7$ & 0.85 & - & - & Miosis \\
\hline $11(M, 66)$ & AL & 2.65 & $3.7-7.0$ & 0.40 & - & - & Miosis \\
\hline $12(\mathrm{~F}, 59)$ & $\mathrm{AL}$ & 5.20 & $4.1-7.3$ & 1.68 & 3.5 & $0.7-3.6$ & Redilatation lag \\
\hline
\end{tabular}

*Familial amyloidosis (transthyretin proline 12).

†Familial amyloidosis (transthyretin proline 52).

CASE DESCRIPTION (PATIENT 1)

A previously healthy woman developed a progressive generalised illness from the age of 57 years. She became nauseated and had increasing anorexia, abdominal colic, and diarrhoea, losing $10 \mathrm{~kg}$ body weight within 3 months. Subsequently she developed pain and weakness in all limbs with wasting, proximal more than distal, loss of tendon jerks, numbness, and hyperaesthesiae. At 18 months there was orthostatic hypotension and a fixed heart rate with almost no response to deep breathing or a Valsalva manoeuvre. There was proteinuria $(1.27 \mathrm{~g} / 24 \mathrm{~h})$, creatinine clearance of 70 $\mathrm{ml} / \mathrm{min}$, and a renal biopsy showed AL amyloid deposits. Pupillometry was done at this stage. Renal function deteriorated further, she developed congestive cardiac failure and died 19-20 months after onset of the illness.

\section{HISTOPATHOLOGY}

Patient 1 died 6 weeks after the autonomic and pupil examinations. The renal biopsy and necropsy samples were processed for conven- tional histology and Congo red staining. ${ }^{15}$ Immunoperoxidase preparations were made from the paraffin embedded blocks and tested for reactivity for AA amyloid protein and $\kappa$ and $\lambda$ light chains by a peroxidase-antiperoxidase technique. ${ }^{16}$

\section{Results}

\section{PUPILLOGRAPHY}

All twelve patients had abnormal pupils. Except for a small degree of anisocoria in patient 2, only one of his resting darkness diameters lying outside the normal range, all the findings were bilateral. The darkness diameters (right eye only for clarity), the diameters expected on the basis of the patients' ages, and the principal characteristics of the pupil reflex responses are shown in the table. Patients 2, 5, 6 , and 9 had tonic pupils which were irregular in outline; they showed poor reflex responses to light and greater but abnormally slow responses to accommodation (fig 1A).

The resting pupil diameters of patients 3, 4, 7,8 , and 12 were within the normal range;
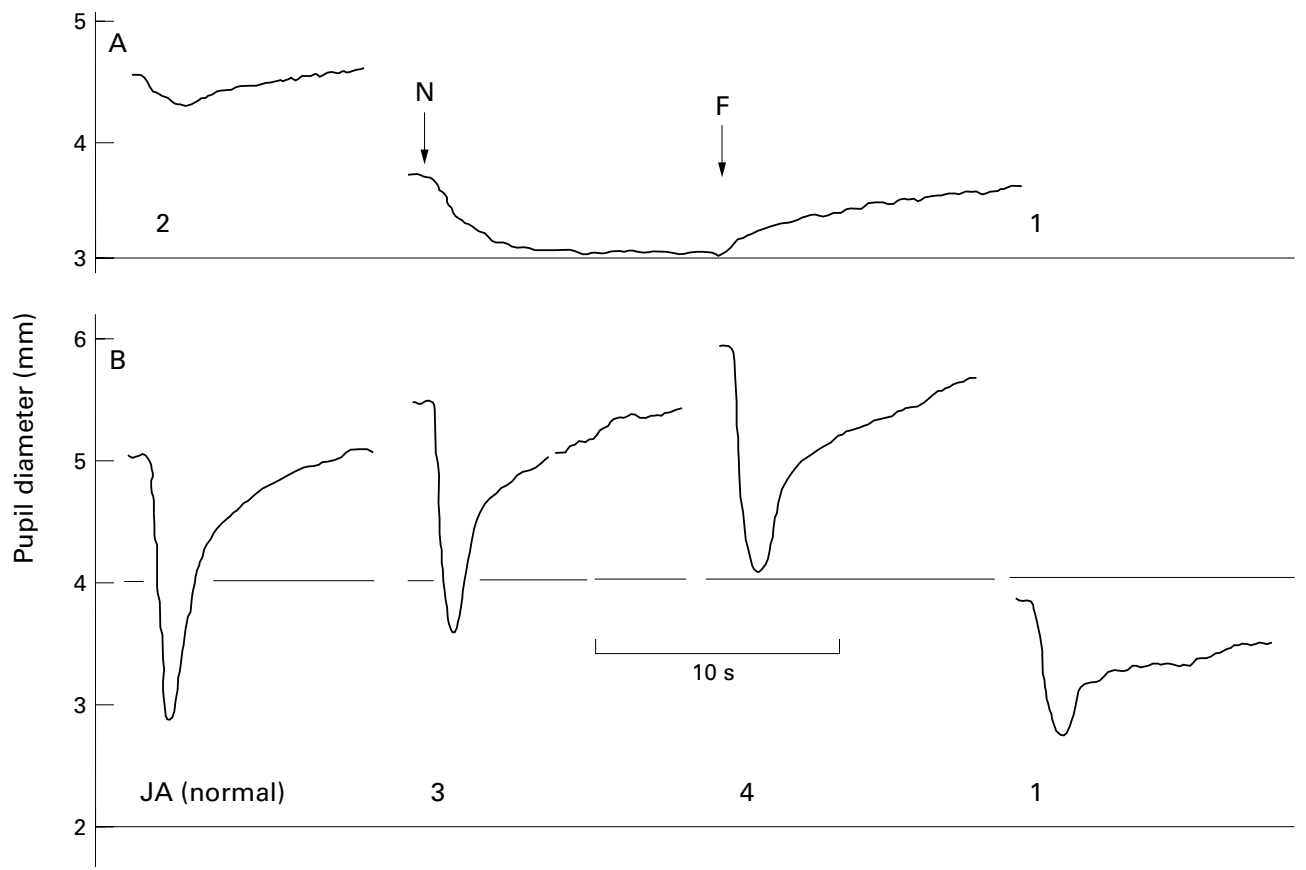

Figure 1 Pupillographic traces of: $(A)$ one patient (2) with responses to a single light reflex and to near $(N)$ and far $(F)$ accommodation showing light-near dissociation and typical tonic responses; (B) one healthy subject and three patients (3, 4, and 1) showing single light reflexes with redilatation lag in the patients. 

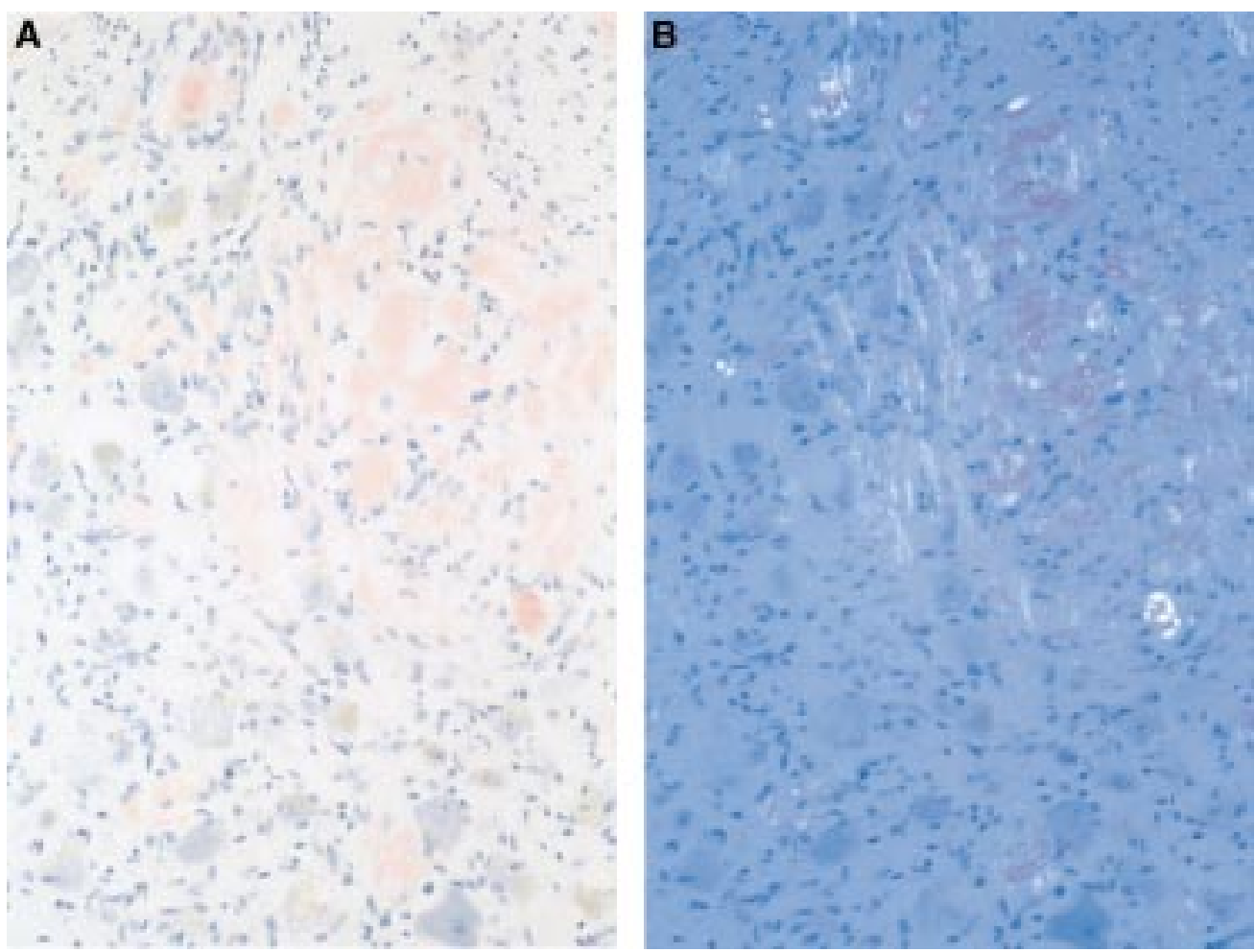

Figure 2 Photomicrographs ( 400$)$ of sympathetic ganglion sections obtained from patient 1 at necropsy. Sections stained with congo red and viewed by conventional light microscopy $(A)$ and between crossed polaroids $(B)$.

those of 1 were abnormally small. All light reflexes were brisk in onset but in each case there was significant redilatation delay (fig 1B).

The pupils of patients 10 and 11 were abnormally small and the light reflexes also small and somewhat slowed. They could not be characterised reliably.

No relation was found between the profile of general autonomic dysfunction and the pattern of pupil abnormality.

\section{HISTOPATHOLOGY}

In the kidney from the index case (1), material with optical staining characteristics of amyloid was found in the glomeruli, interstitium, and arterioles (positive Congo red staining with green birefringence when viewed between crossed polaroids). Fibrillary amyloid was demonstrated on electron microscopy. Immunohistochemistry showed negative staining for amyloid A protein and $\kappa$ light chains but positive staining for $\lambda$ light chains. The amyloid is therefore of the AL type. There was extensive amyloid deposition in many organs at necropsy; in particular there was deposition in the sympathetic ganglia (fig 2 ).

\section{Discussion}

In amyloidosis complicated by autonomic failure we have found abnormal pupils in 12 out of 12 consecutive patients. This estimate of prevalence had a lower 95\% confidence interval of $73 \%$, confirming that pupillary abnormality is indeed common in this situation. Some of these patients had tonic pupils with light-near dissociation, indicating parasympathetic denervation with reinnervation, ${ }^{17}$ whereas others had redilatation lag without loss of the light reflex response or tonicity, which is indicative of sympathetic dysfunction. ${ }^{13}$ In one of the cases with sympathetic disfunction we found deposits of amyloid material in a sympathetic ganglion and associated sympathetic chain. This suggests that some patients have selective parasympathetic, others selective sympathetic, damage.

In a condition characterised by progressive deposition of amyloid material throughout the peripheral nervous system such disparities were unexpected. Our findings should, however, be interpreted with care for minor degrees of dysfunction in one branch of the autonomic nervous system may be undetectable in the presence of severe damage to the other. Most particularly, if a pupil is tonic both constrictor and dilator phases of the light reflex are slowed and detection of selective redilatation lag cannot be achieved. We cannot, therefore, exclude the possibility that most or all of our patients' pupils were affected by damage to both branches of the autonomic nervous system as would be expected from the pathophysiology of the condition. On this basis, it is not surprising that the pupil abnormality in two of our patients could not be characterised, nor in the group as a whole that there was no obvious relation between the profile of the patients' general autonomic dysfunction and their particular apparent pupil abnormality.

We thank the physicians of St Thomas' Hospital and the National Hospital for Neurology and Neurosurgery for permission to study their patients. Dr Philip Hawkins kindly supplied scan information on the types of amyloid in these patients. 
1 Trotter JL, Engel WK, Ignaczak TF. Amyloidosis with plasma cell dyscrasia. An overlooked cause of adult onset

2 Frewin DB, Gilmore HR, Ho JQK, et al. Clinical. physiological and pathological observations in a case of progressive autonomic nervous system degeneration associated with Holmes-Adie syndrome and peripheral neuropathy. Austral Ann Med 1968;17:141-7.

3 Gaan D, Mahoney MP, Rowlands DJ, et al. Postural hypotension in amyloid disease. Am Heart f 1972;84:395-400.

4 Horder JM, Treip CS. Primary amyloidosis with involvement of the peripheral nervous system. Neuropathol Appl Neurobiol 1977;3:297-302.

5 Sandgren 0. Ocular amyloidosis, with special reference to the hereditary forms with vitreous involvement. Surv Oph thalmol 1995;40:173-96.

6 Kelly JJ, Kyle RA, O'Brien PC, et al. The natural history of neuropathy in primary systemic amyloidosis. Ann Neurol

7 De Navasquez S, Treble HA. A case of primary generalised amyloid disease with involvement of the nerves. Brain 1938;61:116-28

8 Chambers RA, Medd WE, Spencer H. Primary amyloidosis with special reference to involvement of the nervous system. $Q \mathcal{F} \mathrm{Med}$ 1958;27:207-26.
9 Burns RJ, Downey JA, Frewin DB, et al. Autonomic dysfunction with orthostatic hypotension. Aust $N Z \mathcal{F} M e d$ 972;1:15-21.

10 Wong VG, McFarlin DE. Primary familial amyloidosis. Arch Ophthal 1967;78:208-13.

11 Witschel $\mathrm{H}$, Mobius W. Augenveränderungen bei generalisierter Amyloidose. Klin Monatsbl Augenheilk 1974;165:61016.

2 Smith SE, Smith SA, Brown P, et al. Pupillary signs in diabetic autonomic neuropathy. BMF 1978;ii:924-7.

13 Pilley S, Thompson HS. Pupillary redilatation lag in Horner's syndrome. Br f Ophthal 1975;59:731-5.

14 Smith SA, Smith SE. Bilateral Horner's syndrome: detection and occurrence. 7 Neurol Neurosurg Psychiatry 1999;66:48-51.

15 Puchtler H, Sweat F, Levine M. On the binding of congo red by amyloid. F Histochem Cytochem 1962;10:355-64.

16 Van Noorden S. Tissue preparation and immunostaining techniques for light microscopy. In: Polak JM, Van Norden $\mathrm{S}$, ed. Immunocytochemistry. Modern methods and applications. 2nd ed. Bristol: Wright, 1986:26-53.

17 Loewenfeld IE, Thompson HS. The tonic pupil: a re-evaluation. Am f Ophthal 1967;63:46-87. 